\title{
Internet guide to travel health.
}

Elizabeth Connor. New York: Haworth Information Press, 2004. I50p. ISBN 07890 I824 I (pbk).

Price: US\$14.95

This is a valuable and useful resource on a variety of health-related issues for the traveller on business or on vacation, with each entry directing the user to relevant web sites. The symbol ž is used to indicate major resources with authoritative and original content, such as the World Health Organisation (WHO). This assists in saving one time in finding the required information.

There is a short introduction on the anatomy of a web address and how to evaluate web content, before moving to general travel health sites; pre-travel planning; specific issues and concerns; diseases, ailments, and ailments; interactive tools (e.g. Jet Lag Calculator); organisations (e.g. International Association for Medical Assistance to Travellers); full-text publications (e.g. International Travel and Health); a glossary of terms which may be unfamiliar to the layperson (preceded by the URLs of medical dictionaries); as well as a detailed index.

This valuable resource covers where to find online information on the necessary health certificates, immunisation and vaccination requirements, and heath insurance before setting out on a journey. It deals with travelling by car, train, air and sea (road safety, airline fatalities, cruise ship travel). There is information on travelling with pets, women travelling alone, seniors travelling alone or with other seniors, children travelling alone or with other children, weather (how to check for forecasts, warnings), natural disasters (for monitoring crisis situations, travelling to disaster areas), death (fatality facts), disabilities (accessible destinations for those with disabilities), and health tourism (for persons seeking surgery abroad, visiting health spas). 
The medical aspects included are regulations on carrying or purchasing medications, medical care while travelling, quarantine, medical contraindications to travel.

The health conditions, diseases and ailments cover avoiding and preventing air and road rage, altitude sickness, motion sickness, fear of flying, diarrhoea, allergies, deep vein thrombosis, malaria, pregnancy, HIV and AIDS, hepatitis, sunburn and heat exhaustion, cold weather conditions, and exercise before and during travel, to name but a few.

A comprehensive resource, with a wealth of information on health and travelling which should fill a valuable place on any library's shelves.

Reviewed by: Yvonne Blomkamp, Information Officer, UCT/MRC Research Unit for Exercise Science and Sports Medicine, Faculty of Health Sciences, University of Cape Town.

Tel: $+27(21) 6504579$

Email: yblomkam@sports.uct.ac.za 